knitting, basket-making, mat-making and brushmaking. Special maps and even pictures are now made for the blind. There are numerous illustrations of these in the volume. The blind children are taught to take part in plays, some of which are complicated enough to tax the powers of those having vision, and, of course, in music of all kinds, many of the blind attain to remarkable proficiency.

The second part of the work deals with the various congresses. These were largely attended, and papers were read which opened discussions on the best methods of teaching the blind. Each congress had its own speciality. Thus at Kiel, I89I, the subject was the modelling of animal forms; and at Berlin, 1898 , it was the teaching of music and grammar. Even comparative grammar was taught to advanced pupils, and those interested in the relationshins of languages will find much that is suggestive in the record of the Berlin conference (pp. 130-I45). At the Paris conference in 1900, the important question was discussed whether blind children should be taught by blind teachers, and, if so, to what extent? There appear to have been considerable differences of opinion upon this point. The French, Belgians, and Italians made great use of blind teachers, but in Germany and other northern countries the greater part of the teaching was done by those who see, and the blind teachers were only helpers. Prof. Kunz has an important article on this question, and he has arrived substantially at the conclusion that the proportion of seeing to blind teachers should be about two to one. Many blind teachers have, however, attained wonderful skill in imparting knowledge to their unfortunate brethren, and a feeling of sympathy and subtle intuitions, related to personal experience, may to some extent account for their success.

One of the most interesting chapters in the volume is that entitled Zur Blindenphysiologie, das sogenannte "Sinnenvikariat" (p. I86). It might be called the "psycho-physik" of the blind. The results of various experimental inquiries are given, and it is shown that in the blind, taking the average of a large number above puberty, all the other senses are capable of more delicate perceptions than in those who can see. As might be expected, the sense of touch is highly developed. This is of great importance, as it enables the blind to use with accuracy the Braille method of designating letters by various patterns of points, which are sometimes sharp and of varying size, sometimes wedge-shaped, and sometimes the marks consist of thin vertical and horizontal lines, either single or meeting at various angles. An address by Prof. Kuntz at Halle, in 1904, gives much information as to the spread over the world of the methods of teaching the blind. This is followed by an interesting description, with numerous illustrations, of the many forms of type suitable for reading, for arithmetic, and for music, and nothing could show more clearly the delicacy of the sense of touch acquired by the blind during their education than an inspection of these curious patterns. Dr. Javal, the eminent Parisian ophthalmologist, contributes an interesting chapter on some physiological features of the blind.

There is an elaborate paper bearing on the perception of the direction of sound by the blind, and the acuteness with which they perceive the nearness and often the nature of objects by reflection of sound-waves. The whole subject has been investigated with the greatest care. It is interesting to find a translation into modern Greek by Fräulein Irene Lascaridi (a teacher in the Asylum for the Blind in Athens) of Prof. Kunz's paper on the physiology of the blind,

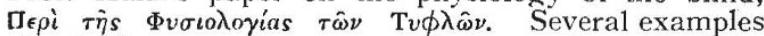
of raised type and maps are shown at the end of the volume. The book is not only worthy as a "Festschrift," as it contains all that can at present be written upon the subject of the education of the blind, but it will be an enduring monument to the zeal, devotion, and learning of Prof. M. Kunz, who has devoted his life to the interests of those who are deprived of one of the most important of the senses.

JOHN G. MCKendRICK.

\section{CATALOGUE OF DOUBLE STARS.1}

PROF. G. W. HOUGH, director of the Dearborn Observatory, while observing with the $18 \frac{1}{2}$-inch refractor, discovered 648 double stars. These stars consist of close pairs and of pairs where the companion is very faint; they are, therefore, difficult to measure, and may be regarded as of the same class as those discovered by Prof. Burnham. But whereas the Burnham stars have been fairly well observed and yield a good percentage of binaries, the Hough stars have been very little observed, and they yield few interesting pairs.

Prof. Doolittle, of the Flower Observatory, has done good work in collecting these 648 stars in one catalogue, and arranging this catalogue in a form which leaves nothing to be desired. The stars are not entered according to the Hough number, but in order of right ascension, and the meridian catalogue name is added; but to facilitate reference, a list of the stars is given in order of the Hough number, with the page in the catalogue on which the star appears.

In addition to his own measures, made at the Flower Observatory of the University of Pennsylvania, Prof. Doolittle gives measures by other observers, which unfortunately are few. From the Astronomer Royal's report and from the Greenwich results published in the Monthly Notices of the R.A.S., we gather that the Greenwich observers have been at work on the Hough stars, and it seems a pity that more of these measures could not be included. It may be that Prof. Doolittle experienced difficulties in publication which retarded the appearance of his catalogue. This would make it seem of later date than it really is, and would also explain the phrase in the introduction-" Mr. Burnham's new general catalogue, when it is published," \&c. The general catalogue has been with us since August last.

The right ascensions and declinations are given for I880. This, in a catalogue of 1908 , means that the right ascensions are practically $I_{2} \frac{1}{2} \mathrm{~m}$. wrong to start with, and the declinations sometimes $8^{\prime}$. or $g^{\prime}$ out, thus necessitating the application of precession corrections by everyone using the work, whereas if the places had been given for I9Io they would have been useful for many years.

Prof. Doolittle began systematic work in I90I, and the catalogue he has produced is an important piece of work well carried out, and the printing is very good, the few errors being easily rectified. But owing somewhat to the uninteresting character of the Hough stars, he has had little beyond the actual catalogue itself to repay him for his labour. With the exception of Hough 2I2, and possibly two others, there is no object in the whole catalogue of any remarkable interest at present; and the paragraph on p. Io of Prof. Doolittle's introduction must evidently be read in the light of the well-known characteristics of the Hough stars. In this paragraph he gives thirty pairs as being clearly binary systems in rather rapid motion.

Astonishment at the large number was increased on an analysis of the thirty. From the notes in the

1 "Catalogue and Re-measurement of the 648 Double Stars discovered by Prof. G. W. Hough." Publications of the University of Pennsylvania, Astronomical Series, vol. iii., part iii. Pp. 176 . (Pennsylvania, 19o7.) NO. 202 I, VOL. 78$]$ 
body of the work, i.e. in Prof. Doolittle's own words, we find these consist of two pairs in which there is no evidence of motion; five pairs in which change is doubtful; five pairs in. which some change is probable; seven pairs where the change is less than ${ }^{\circ}{ }^{\circ} \mathrm{O}$ per annum; six pairs where the change is just over $\mathrm{I}^{\circ} \circ$ per annum; two pairs where it is approximately $2^{\circ}$ O per annum; two pairs fairly rapid binaries; one pair, Hough 212, with a period of 5.7 years.

The last five only can be brought under the above phrase.

There are two rather serious errors in identification: Hough 198 should be B.D. $+16^{\circ} .4896$, not WB (2)xxiii. 195 , the declination of which is $42^{\circ}$, not $16^{\circ}$; Hough 507 should be WB(2)iv.r. 5 , declination $37^{\circ}$, not $W B(2)$ iv. 154 , declination $32^{\circ}$.

\section{NOTES.}

WE regret to see the announcement of the death on July 20 of Mr. Arthur Lister, F.R.S., distinguished particularly for his researches on the Mycetozoa. Mr. Lister was seventy-eight years of age, and was elected a Fellow of the Royal Society in 1898 .

Sir John BANks, first president of the Royal Academy of Medicine, Ireland, and a leading authority on mental diseases, died on July 16 at ninety-seven years of age.

THE eighth mecting of the Association of Economic Biologists will be held at Edinburgh on Tuesday, Wednesday, and Thursday, July 28, 29, and 30 , under the presidency of Mr. A. E. Shipley, F.R.S., who will deliver a presidential address "On Rats and their Parasites" on July 28 .

WE learn from the Journal of the Meteorological Society of Japan that the death of H.I.H. Prince Yamashina occurred on May 2 at thirty-one years of age. The late Prince had deep interest in meteorology and allied sciences. On his own account he established the Mount Tsukuba meteorological observatory and two base stations in rgor, and published a series of "Ergebnisse der meteorologischen Beobachtungen auf dem Tsukubasan." $\mathrm{He}$ made several valuable researches in meteorology and seismology, and designed a number of excellent instruments.

DR. Ludwig Mond, F.R.S., has offered to the Reale Accademia dei Lincei a biennial international prize of 4ool., to be called the Stanislao Cannizzaro prize, for chemistry and physical chemistry. The amount necessary for providing the prize, together with taxes and expenses, is to be given by the donor in the form of Italian Consols, while the conditions of award have been placed in the hands of the president of the Academy, in consultation with Dr. Mond and Senator Cannizzaro.

THE Paris correspondent of the Times states that a Society of the Observatories of Mont Blanc has just been regularly constituted, with a board of directors largely chosen from the Academy of Sciences, for the more systematic continuation of the work begun by the late $M$. Janssen and M. Vallot. The society has decided to place the Vallot and Janssen observatories under the direction of M. Vallot. With this object the latter has given his establishment to the socicty just formed-a purely scientific association-which appeals for members and funds. The secretary is Comte de La Baume-Pluvinel, 9 Rue de La Baume, Paris.

WE are informed that the optical illusion observed by Dr. T. Terada, Tokyo, and described on p. 255 of our last number, has been previously observed and described.
In the Proc. Roy. Soc., Edin., $1878-79$, there is an account of some experiments on this illusion. Like Dr. Terada, the writer first observed it after looking at moving water, but in his case it was a quickly flowing stream; on afterwards looking at the gravel bank a stream of gravel seemed to flow slowly through it in a direction the opposite. of that of the water. A number of experiments are described in the paper referred to on the effect of looking at rotating discs with black and white radii, and moving bands of paper with cross-lines, the eyes being afterwards directed to a mottled surface on which the reverse movements referred to appeared. These spectra were shown to be entirely stopped when a straight line was drawn across the surface.

AN international exhibition and congress of the applications of electricity will be held on September $\mathrm{I}_{4-20}$ at Marseilles. The object of the congress is the consideration of the technical, commercial, and administrative problems which have arisen in recent years. These questions will be treated in reports prepared by well-known authorities, and the reports will be submitted to the congress for discussion, and published subsequently. The business of the meeting will be transacted in nine sections dealing with, respectively, the framing of regulations; the construction and protection of electric wiring; technical and commercial workings; lighting and domestic applications; applications to industry, mines, traction, and agriculture; electro-chemistry and electro-metallurgy ; telegraphy and telephony; instruction and measurements; and applications to hygiene and medicine. Numerous papers, none of which, we understand, is the work of a British authority, will be discussed in each section. Prof. Maurice Lévy will be the president of the congress. There are four general secretaries, MM. Armagnat, Chaumat, and Dusaugey, and Prof. Zimmern, who may be addressed at $6_{3}$ Boulevard Haussmann, Paris.

Commander Peary departed on July 17 from Sydney, Nova Scotia, on the Roosevelt, on his voyage to the North Pole. A Times correspondent reports that Commander Peary has summarised the main features of his programme thus: First, the utilisation of the Smith Sound route, the advantages of which are a land base roo miles nearer the Pole than is to be found at any other point of the entire periphery of the Arctic Occan, a long stretch of coast-line upon which to return, and a safe and (to Commander Peary) well-known line of retreat in the event of any mishap to the ship, independently of assistance. Secondly, the selection of a winter base which commands a wider range of the central polar sea and its surrounding coasts than any other base in the Arctic regions. Cape Sheridan is practically equidistant from. Crocker Land, from the remaining unknown portion of the north-east coast of Greenland, and from Pcary's " Nearest the Pole", of 1906. Thirdly, the use of sledges and Esquimaux dogs. "Man and the Esquimaux dog," Commander Peary observes, " are the only two machines capable of such adjustment as to meet the wide demands and contingencies of Arctic travel. Airships, motor-cars, trained Polar bears, \&c., are all premature, except as a means of attracting public attention." Fourthly, the use of the Whale Sound Esquimaux for the rank and file of the sledge party.

THE president of the Local Government Board has authorised for the current year the following researches in connection with the annual grant voted by Parliament in aid of scientific investigations concerning the causes and proresses of disease:-(1) A further inquiry by Dr. M. H. Gordon into the character and differential tests for the

NO. $202 \mathrm{I}$, VOL. 78] 